\title{
Educação em saúde para gestantes da zona rural: um relato de experiência
}

\author{
Health education for pregnant women in rural \\ area: a report of experience
}

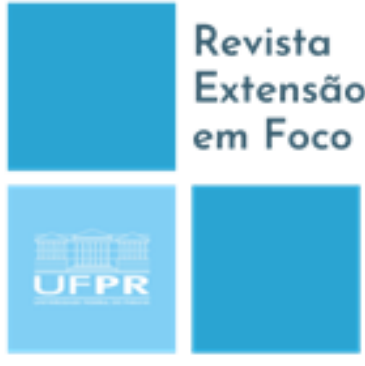

ISSN 2358.7180

\section{Jhescyka Ahlessan Bueno da Luz ${ }^{1}$, Ana Paula Xavier Ravelli², Margarete Aparecida Salina Maciel $^{3}$}

\begin{abstract}
RESUMO
A gestação é um momento de transformações na vida da mulher e de toda a família, com progressivas mudanças fisiológicas, biológicas, psicológicas e sociais. $\mathrm{O}$ acompanhamento pré-natal com a realização de consultas e exames garante a qualidade na assistência e nesse processo, a educação em saúde é fundamental. $\mathrm{O}$ objetivo deste estudo foi relatar a experiência vivenciada por discentes, com atividades educativas desenvolvidas de 2016 a 2018 com grupos de gestantes no evento extensionista "Oficinas de orientação e educação em saúde para gestantes da comunidade rural de Itaiacoca" abordando temas relacionados. Empregou-se roda de conversas e outras atividades com resultados positivos, tanto para a formação e vivência profissional da discente de enfermagem como para a comunidade atendida, beneficiando o empoderamento da gestante no cuidado materno-infantil. Possibilitou melhora na qualidade da assistência prestada e na educação em saúde com a inclusão de novos temas e ações complementares, como o tratamento odontológico.
\end{abstract}

Palavras-chave: Cuidado Pré-Natal. Zona Rural. Relações Materno-Fetais. Promoção da Saúde. Capacitação Profissional.

\section{ABSTRACT}

Pregnancy is a moment of transformation in the life of the woman and the whole family with physiological, biological, psychological and social changes. Prenatal follow-up with consultations and examinations guarantees quality in health care and in this process, health education is fundamental. The objective of this study was to the report the student's experience with educational activities developed from 2016 to 2018 with groups of pregnant women in the extension event "Health orientation and education workshops for pregnant women in the rural community of Itaiacoca" addressing related topics. Rounds o conversation and other activities was used, with positive results both for the training and professional experience of the nursing student and for the community attended, benefiting the empowerment of the pregnant woman in maternal and child care. It has improved the quality of care and health education with the inclusion of new themes and complementary actions, such as dental treatment.

Keywords: Prenatal Care. Rural Areas. Maternal-Fetal Relations. Health Promotion. Professional Training.

${ }^{1}$ Graduada - Bacharelado em Enfermagem. Universidade Estadual de Ponta Grossa (UEPG), Ponta Grossa, Paraná, Brasil. E-mail: jhescykaahlessan@ hotmail.comail.com. Orcid: https://orcid.org/0000-0002-8603$\underline{3131}$

${ }^{2}$ Doutora Em Enfermagem. Universidade Estadual de Ponta Grossa (UEPG), Ponta Grossa, Paraná, Brasil. E-mail: anapxr@hotmail.com. Orcid: https://orcid.org/0000-0003-4095-758X

${ }^{3}$ Doutora em Ciências Biológicas - área de Microbiologia Aplicada. Universidade Estadual de Ponta Grossa (UEPG), Ponta Grossa, Paraná, Brasil. E-mail: masalina@uepg.br. Orcid: https://orcid.org/0000-0001$\underline{5688-6195}$ 


\section{INTRODUÇÃO}

A descoberta da gravidez é um momento de turbilhões de sentimentos e de transformações para a vida da mulher e de toda a família; é o período que representa a formação de um novo ser. Surgem daí sentimentos de dúvidas, receios, ansiedade e surpresas, tornando-se um momento que necessita de tempo para se adaptar a essa nova fase na vida (BRASIL, 2016c). É indiscutível que a mulher passará por progressivas mudanças, sejam elas fisiológicas, biológicas, psicológicas ou sociais no período gestacional. Esse período compreende uma experiência única na vida da mulher, com expectativas e sentimentos múltiplos, diferentes de pessoa para pessoa e em cada gestação.

No primeiro trimestre essas alterações são mais expressivas, com mudanças de humor, paladar, sonolência, náuseas, dúvidas, medos e insegurança, relacionadas à maternidade (QUEROZ, 2012). As alterações ocorridas durante a gravidez sejam elas pequenas ou marcantes, deverão ser compartilhadas com profissionais da saúde na realização do pré-natal.

O Ministério da Saúde caracteriza a atenção pré-natal como o período que compreende desde a concepção até o início do trabalho de parto, e preconiza um mínimo de seis consultas durante a gestação e uma no puerpério. Esclarece ainda, que o início precoce do pré-natal no primeiro trimestre de gestação, é fundamental para prevenção, detecção de doenças maternas ou fetais, esclarecimento de dúvidas e encaminhamento para exames e vacinas, entre outros. (BRASIL, 2013; 2016ab).

Segundo Carrara e Oliveira (2013, p.99):

O principal objetivo do atendimento no pré-natal é acolher a mulher nesse processo de mudanças físicas, mentais e sociais, conquistando com isso a confiança da mulher a entregar aos cuidados da equipe de saúde o seu corpo e sua família, trazendo a ela a autonomia durante a gestação e o parto.

$\mathrm{Na}$ zona urbana a gestante tem mais facilidade ao acompanhamento do pré-natal, diferente do que ocorre na zona rural que apresenta dificuldades devido a meios de 
transporte, distâncias, condições de estradas afetadas pelas variações climáticas que dificultam o acesso até a unidade básica de saúde, diminuindo dessa forma a adesão ao pré-natal (PAULA, 2013). Outros fatores como a aceitação da gravidez, o apoio, a idade, o acolhimento e a assistência profissional também influenciam nessa adesão (ROCHA; BARBOSA; LIMA, 2017).

Para tentar solucionar situações como as citadas, a territorialização em saúde permite conhecer a realidade de uma determinada população atendida pela unidade básica com Estratégia de Saúde da Família, a fim de reorganizar o serviço conforme as necessidades detectadas e verificar a efetividade das ações implantadas, visto que a Atenção Primária à Saúde é a porta de entrada para os demais serviços de saúde (CAIRES; JUNIOR, 2017; JUSTO et al., 2017). É na atenção primária que as gestantes serão classificadas, conforme riscos presentes em sua condição de saúde, como gestação de risco habitual, intermediário ou alto risco e serão então vinculadas aos serviços de maior complexidade se necessário (PARANÁ, 2018).

Na grande maioria dos casos, a primeira consulta da gestante é com a equipe de enfermagem, momento este em que se realiza anamnese, histórico familiar, obstétrico e de doenças sexuais, rotinas alimentares, urinário e intestinal (CARRARA; OLIVEIRA, 2013). A atuação do profissional de enfermagem no acolhimento e da equipe na assistência pré-natal é que mostrará à gestante a necessidade do acompanhamento, a prevenção e os serviços que estão disponíveis para utilização neste período gestacional.

De acordo com o Ministério da Saúde e conforme garantido pela Lei do Exercício Profissional, regulamentada pela Lei $\mathrm{n}^{\mathrm{o}} 7.498 / 86$, "o profissional enfermeiro pode acompanhar inteiramente o pré-natal de baixo risco na rede básica de saúde" (BRASIL, 1986; 2013).

Entre as atividades desenvolvidas pelo profissional de enfermagem encontra-se a educação em saúde, processo que envolve ensinar, aprender, orientar, esclarecer, saber ouvir e aumentar assim a compreensão das gestantes sobre a necessidade de participação no pré-natal, para que as futuras mães, no momento do parto, cheguem instruídas, preparadas e confiantes (BORGES, 2015; CARRARA; OLIVEIRA, 2013).

Existem várias formas de promover a educação em saúde e uma delas é na sala de espera, onde as gestantes estão aguardando o atendimento individual. Pode-se realizar uma roda de conversa em conjunto, fazendo abordagens de temas como a importância do 
aleitamento materno, cuidados com as mamas, cuidados com o bebê, parto, alimentação, saúde bucal, entre outros (CAMILLO et al., 2016). Outra maneira, é no atendimento de relatos e queixas do cotidiano da gestante, sendo possível transmitir a educação em saúde por meio de esclarecimento de dúvidas de forma individual. Ainda, em reuniões mensais com tema já proposto e com desenvolvimento de atividades lúdicas, a educação em saúde, permite melhor participação e aprendizado (BORGES, 2015; CAMILLO et al., 2016).

Para uma boa qualidade na assistência à saúde, é fundamental o conhecimento do perfil das gestantes, pois fatores como idade, número de gestações, escolaridade, situação conjugal, ocupação, entre outros, podem influenciar na saúde materna. Segundo Barbosa et al. (2017) a busca de indicadores locais individualizados e específicos, permitem a elaboração e a adoção de medidas que visam corrigir os problemas que interferem na qualidade da assistência à saúde.

Considerando o contexto apresentado, o objetivo principal deste trabalho foi relatar a experiência vivenciada pela autora, sobre as atividades educativas desenvolvidas junto ao grupo de gestantes da zona rural de Itaiacoca, Ponta Grossa-PR, no evento extensionista "Oficinas de orientação e educação em saúde para gestantes da comunidade rural de Itaiacoca", abordando temas relacionados com a gestação e cuidados com a criança.

\section{MÉTODOS}

Trata-se de um estudo qualitativo com relato de experiência da intervenção desenvolvida em duas unidades com Estratégia de Saúde da Família (USF) do Distrito de Itaiacoca, no município brasileiro de Ponta Grossa, Paraná. As duas USF localizam-se em região rural, uma na localidade de Biscaia e a outra na localidade Cerrado Grande (Centro Rural Universitário de Treinamento e Ação Comunitária - CRUTAC), ambas pertencentes à Secretaria Municipal de Saúde da Prefeitura Municipal de Ponta Grossa, (Figura 1). O terreno em que está estabelecida a USF do CRUTAC pertence à Universidade Estadual de Ponta Grossa (UEPG). No local são desenvolvidas desde 1976 várias ações extensionistas para a região de Itaiacoca, quando da criação do Programa CRUTAC (SCHAFRANSKI, 1982). 
Figura 1 - Localização das Unidades Básicas de Saúde da Família de Biscaia e de Cerrado Grande (CRUTAC UEPG) em relação ao campus Uvaranas da UEPG

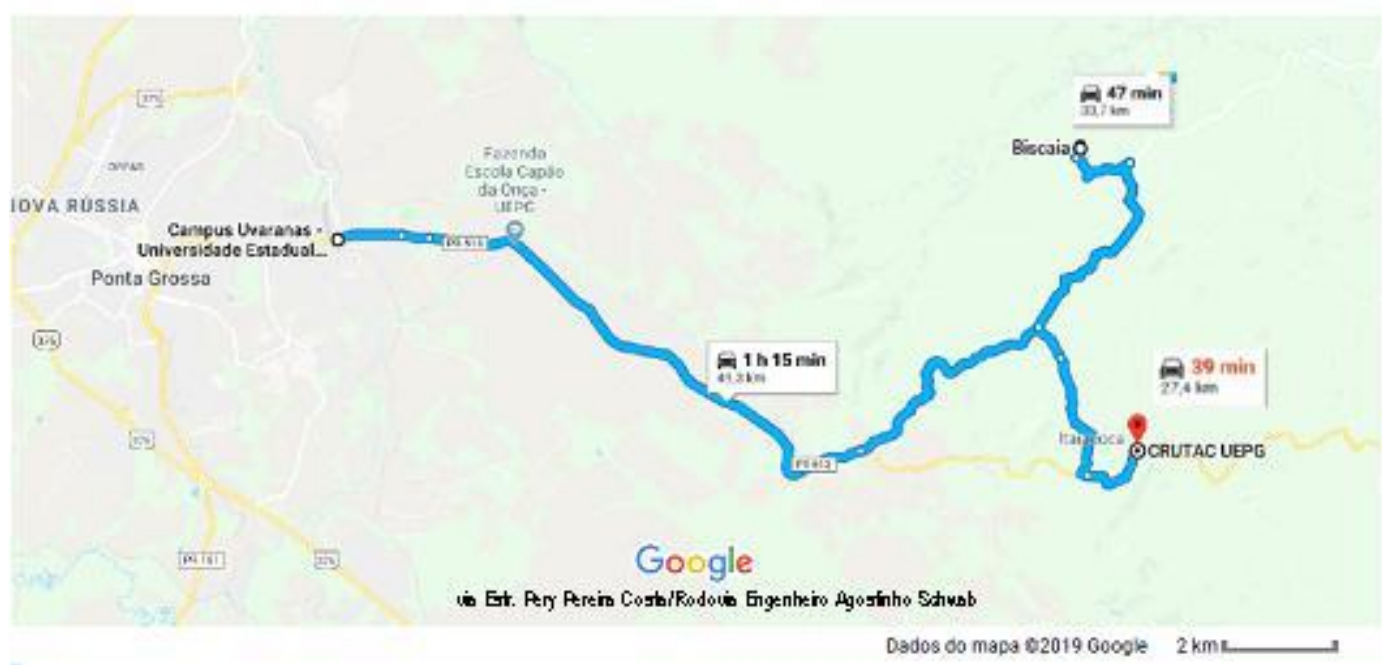

Fonte: https://www.google.com/maps/dir/. Acesso em: 30 maio 2019

Atualmente existem sete USF que atendem a diversas localidades de Itaiacoca distribuídas nas regiões de Cerrado Grande, Mato Queimado, Roça Velha, Carazinho, Sete Saltos, Biscaia e Pocinhos. Nelas atuam o mesmo médico e enfermeira e todas as gestantes são encaminhadas para seguimento do pré-natal nas duas USF em que foi realizado o trabalho.

A intervenção foi proposta como o evento extensionista "Oficinas de orientação e educação em saúde para gestantes da comunidade rural de Itaiacoca", vinculado ao projeto de extensão "Avaliação laboratorial na assistência à saúde e prevenção de doenças - Programa CRUTAC".

As 55 gestantes cadastradas nas USF e seus acompanhantes foram convidados a participar das oficinas em saúde no início do período pré-natal, independente do tempo de gestação já decorrido, e sendo agendadas concomitantemente às consultas médicas do período gestacional. Gestantes que não aceitaram o convite foram excluídas do estudo (n =3). A metodologia adotada foi a roda de conversa (MELO et al., 2016) associada à atividades lúdicas, vídeos, atividades práticas e demonstrativas.

Ainda, foi realizado um questionário semi-estruturado às gestantes, com a finalidade de traçar o perfil sociodemográfico. As perguntas foram aplicadas pela equipe das oficinas, na forma de entrevista individualizada. 
$\mathrm{O}$ risco gestacional foi determinado pela enfermeira-chefe, que acompanhou o período gravídico-puerperal das participantes.

Os temas trabalhados foram específicos ao período gestacional, puerperal e primeiros anos de vida da criança, selecionados pela equipe das oficinas e por solicitação das participantes. Alguns foram reforçados com folhetos informativos confeccionados pela equipe e distribuídos às gestantes.

A equipe de trabalho foi constituída por três discentes do curso de Enfermagem e Saúde Pública, orientados por uma professora do curso de Farmácia da UEPG. Eventualmente houve a participação de outros convidados como discentes do curso de Odontologia, de Enfermagem e Saúde Pública e também uma Doula. Houve ainda parceria com a Equipe da Prefeitura Municipal de Ponta Grossa, composta por uma enfermeira, duas auxiliares de enfermagem e quatro agentes comunitários que participaram na captação de gestantes, no reforço do convite para participar das reuniões e nos cuidados inerentes às suas funções.

Os encontros ocorreram uma vez ao mês em cada USF, com duração aproximada de duas horas. A sala destinada às oficinas foi preparada de modo a deixar o ambiente acolhedor, com cartazes alusivos à gestação e uma mesa de lanche.

Os resultados das oficinas foram analisados pela equipe, considerando-se questionários utilizados antes e após as atividades, a participação e interatividade com as demais gestantes e com a equipe e a avaliação pessoal das gestantes, ao final da oficina. Para cada tema, utilizou-se uma estratégia de abordagem e avaliação da oficina.

O relato de experiência foi desenvolvido de forma descritiva e compreendeu o período de maio de 2016 a dezembro de 2018, observando os preceitos éticos com aprovação do Comitê de Ética em Pesquisa da UEPG (Parecer nº 3.067.226/2018).

\section{RESULTADOS E DISCUSSÃO}

Durante o período estudado, participaram do evento de extensão um total 52 gestantes, sendo $28(53,8 \%)$ atendidas na USF do CRUTAC e $24(46,2 \%)$ na USF do Biscaia. A idade das gestantes variou de 14 a 45 anos (24 \pm 7$)$, sendo 17 (32,7\%) destas 
primigestas, e em relação ao estado civil, houve predomínio de gestantes casadas ou unidas não oficialmente $(46 ; 88,5 \%)$.

Quanto ao risco gestacional, todas foram classificadas como de baixo risco ou risco habitual, sendo acompanhadas na USF mais próxima da residência e vinculadas ao Hospital Universitário Regional dos Campos Gerais (Hospital Universitário Regional Wallace Thadeu de Mello e Silva) para intercorrências e nascimento do bebê. Uma gestante da UFS Biscaia foi reclassificada como gestação de alto risco por apresentar episódios de Epilepsia, sendo encaminhada para o acompanhamento no Centro de Saúde da Mulher e vinculada à Santa Casa de Misericórdia de Ponta Grossa.

As USF que fizeram o acompanhamento dos pré-natais seguem o protocolo da Linha Guia Mãe Paranaense (PARANÁ, 2018), sendo que todos os protocolos clínicos, reconhecidos como padrão pela Rede Mãe Paranaense, foram editados pelo Ministério da Saúde. A integralidade da atenção na gestação envolve não somente os aspectos físicos, mas também fatores emocionais, relações sociais, contexto familiar e comunitário. Assim, independente de ser a primeira gestação ou não, envolve mudanças na vida da mulher e o desencadeamento de sofrimentos e sentimentos ambíguos são comuns neste período. Portanto, o apoio familiar e a relação acolhedora dos profissionais de saúde desempenha papel importante para o entendimento dessas alterações (BRASIL, 2013).

\section{RELATO DE EXPERIÊNCIA}

A solicitação das ações de educação em saúde com as gestantes foi da enfermeira das USF, que sentiu a necessidade da implantação de uma atividade mais acolhedora e que promovesse a informação, orientação e esclarecimentos de dúvidas. Essas atividades se iniciaram em 2015 porém, o relato compreende o período que a autora, como aluna do curso de Enfermagem e Saúde Pública, pôde participar ativamente e contribuir com o evento para as gestantes.

Os temas abordados muitas vezes se repetiam, por mudança do público alvo, por necessidade de abordagem ou por solicitação das gestantes.

\section{TEMAS}




\section{Primeiros mil dias: a importância de nutrir, cuidar e estimular}

Foi o primeiro tema a ser trabalhado, pois abrange todos os temas relacionados à gravidez. Os primeiros 1000 dias representam um importante período no qual se pode garantir a qualidade de vida materno-infantil e que irá definir a fase adulta do bebê e todo seu ciclo de vida, diminuindo a chance do ciclo intergeracional da pobreza (Primeiros 1000 dias, 2016; CUNHA; LEITE; ALMEIDA, 2015).

Neste encontro foi apresentado um pequeno vídeo que mostra cenas de cuidados, atenção, estímulo e afeto com o bebê, apontando atitudes positivas dos pais que contribuem com o crescimento e desenvolvimento saudável. Os cuidados dos primeiros 1000 dias começam na concepção (270 dias de gravidez), somados aos 365 dias de 0 a 12 meses e mais 365 dias de 13 a 24 meses, ou seja, até os 2 anos.

Na roda de conversa estimulou-se a reflexão sobre as decisões tomadas pelas mães gestantes e como estas podem influenciar desde aquele momento, na formação, desenvolvimento físico, intelectual e afetivo do bebê, interferindo positiva ou negativamente por toda a sua vida.

\section{Importância do pré-natal, exames laboratoriais e mudanças corporais}

No início do encontro foi aplicado um questionário para avaliar os conhecimentos prévios das gestantes sobre o tema. No segundo momento, houve uma pré-exposição do tema, da importância do acompanhamento da gestação desde o início (primeiro trimestre) com a realização de testes rápidos para detecção do vírus da imunodeficiência adquirida, sífilis e hepatites B e C; ainda o teste da mãezinha, capaz de detectar precocemente a presença de hemoglobinopatias e outros exames laboratoriais. É no pré-natal que é possível acompanhar o desenvolvimento do bebê e detectar problemas fetais como má formação, sendo possível em algumas, situações o tratamento intrauterino se em fases iniciais (BRASIL, 2013; 2016a).

O Ministério da Saúde preconiza no mínimo seis consultas no pré-natal, alternando consulta médica e de enfermagem (BRASIL, 2013). De acordo com o protocolo da mãe paranaense, são no mínimo sete consultas, sendo seis durante o pré-natal e uma no puerpério (PARANÁ, 2018). As consultas iniciais são mensais e com o avançar da gestação passam a ser quinzenais e por fim, semanais em ambos os protocolos, pois a préeclampsia, a eclampsia e o parto prematuro são intercorrências comuns no terceiro 
trimestre. O acompanhamento é essencial para a saúde perinatal, auxiliado por exames laboratoriais e complementares como ecografia obstétrica, entre outros, além do acompanhamento odontológico.

Enfatizou-se a vacinação na gestação, dentre elas a vacina influenza, tríplice bacteriana e hepatite B (BRASIL, 2013; 2016b; PARANÁ, 2018).

Deu-se início a roda de conversas com abertura para perguntas, trocas de experiências e inseriu-se o tema das mudanças corporais e emocionais. Questionadas sobre o sentimento ante a gravidez, surgiram relatos de medo, felicidade, nervosismo, ansiedade, sensibilidade e choro sem motivo aparente. E em relação a mudanças fisiológicas destacaram a náusea, azia, sono, falta de ar, cólicas e aumento da frequência ao urinar. Diante das percepções e constatações das mudanças ocorridas entre as gestantes, enfatizou-se o apoio familiar. Outras orientações envolveram as mudanças de hábitos alimentares para alívio de náuseas e azias; estímulo à caminhada para regulação do intestino; repouso; uso de sutiã de sustentação, dentre outros.

As mudanças emocionais decorrem das mudanças biológicas, acarretando em fragilidade emocional (BRASIL, 2013). Leite et al. (2014) destacam o surgimento de sentimentos contraditórios que se transformam ao longo da gestação, estando associados a fatores como gravidez não planejada, questões econômicas, falta de apoio familiar entre outros, como pôde ser detectado nas participantes do presente estudo.

Ao final desse encontro, foi aplicado novamente o questionário e observado uma melhora no desempenho das respostas.

\section{Alimentação na Gestação}

A dinâmica empregada neste encontro foi a montagem de uma mesa com brinquedos, figuras, grãos de arroz e feijão em panelas, representando alimentos variados como frutas, legumes, verduras, leite, pão, doces, bolos, carnes, ovos, linguiças, sucos, achocolatados, refrigerantes, Ketchup, mostarda, macarrão. Cada gestante apresentou seus hábitos alimentares.

A seguir explicou-se que durante a gestação e período de amamentação é necessário mudanças alimentares, que sejam mais saudáveis, pois tudo o que se ingere é transmitido ao bebê (TEIXIERA et al., 2015). Enfatizou-se a importância de fracionar a alimentação 
durante dia, para atenuar a fome em excesso e não gerar uma sobrecarga nutricional; quais os nutrientes que são importantes em cada fase tais como o ácido fólico, que é vital para o desenvolvimento do sistema nervoso do bebê, bem como fontes de proteínas, ferro, cálcio e vitaminas. Orientou-se a substituição dos carboidratos simples por alimentos integrais e a ingestão de 2 litros de água diariamente, pois auxilia no trânsito intestinal. Destacou-se que refrigerantes e embutidos são ricos em açúcar e fontes de calorias vazias, contendo conservantes e corantes, estão relacionados ao ganho de peso materno e interferem na nutrição fetal e, portanto, devem ser evitados (TEIXIERA et al., 2015).

Para finalizar o encontro, as gestantes refletiram sobre a alimentação atual e fizeram uma autoavaliação. A maioria delas admitiu que precisava melhorar os hábitos alimentares. No entanto, uma gestante adolescente mesmo depois da oficina não percebeu as falhas em sua alimentação.

Foram entregues exemplares de cardápios, a fim de que as gestantes pudessem adaptar sua nutrição, de acordo com as orientações para cada trimestre gestacional. No primeiro trimestre recomenda-se a ingestão de alimentos ricos em ferro e ácido fólico, no segundo alimentos contendo cálcio e vitamina $\mathrm{D}$, essenciais para o crescimento de ossos e dentes fortes e no terceiro trimestre, combinações alimentares que proporcionam uma verdadeira recarga de baterias e energia (TEIXIERA et al., 2015).

\section{Saúde Bucal}

Nesta oficina foi utilizado como material de apoio a "Cartilha da Gestante: Cuidado com a Saúde Bucal", de Rocha et al. (2015). Foi aplicado previamente um questionário para avaliar o conhecimento das gestantes sobre o tema e em seguida deu-se início a roda de conversa, finalizando com as mesmas perguntas.

Durante a roda, a intermediadora utilizou recurso audiovisual para estimular a participação com perguntas e imagens da cartilha. Abordou-se a importância do acompanhamento odontológico durante a gestação e as alterações frequentes na saúde bucal. Reforçou-se a necessidade de higienização, pois nessa fase o consumo de alimentos é mais frequente e o descuido com a higiene oral pode ocasionar cáries, tártaros e gengivites que são detectados por profissional da área da saúde bucal. O não tratamento dessas condições pode afetar o desenvolvimento e a saúde do bebê e até um parto prematuro. Foi ensinado a escovação adequada e os cuidados com a higiene bucal do bebê 
desde antes da erupção dos dentes de leite, utilizando gaze ou fralda de pano, água filtrada ou fervida e após o surgimento destes, iniciar a escovação e agendar consulta odontológica para avaliação e orientação profissional e, dessa forma, iniciar o costume desde bebê a hábitos de saúde bucal (ROCHA et al., 2015).

Muitas dúvidas e medos foram detectados na fala das gestantes. Uma pergunta em que as respostas foram divergentes foi sobre "o que fazer após episódios de vômitos?". Esclareceu-se que após esses episódios, a ação do suco gástrico na boca, pode desgastar o esmalte dos dentes pela perda de sais de cálcio, tornando-os mais sensíveis. Para evitar que isso ocorra não se devem escovar os dentes em seguida, mas sim enxaguar a boca com água e bicarbonato de sódio para neutralização do ácido e mais tarde, escovar utilizando escova de cerdas macias (RESES, 2017).

Outra dúvida esteve relacionada ao enfraquecimento dos dentes da mãe porque o bebê "rouba" o cálcio para formação de sua dentição. Foi explicado que isto é um mito, e que o cálcio utilizado para a formação dos dentes do bebê, provém da alimentação materna e, portanto, esta deve ser rica em leites, queijos e derivados (ROCHA et al., 2015).

Em relação ao tratamento odontológico no período gestacional foram constatadas muitas dúvidas, principalmente sobre o uso de anestesia e radiografia, como demonstrado nas falas:

"...Ouvir dizer que gestante não pode tomar anestesia, faz mal para o desenvolvimento do nenê..." (Grávida 15).

"...Preciso fazer tratamento de canal, mas farei somente depois que o bebê nascer, pois tenho medo da anestesia..." (Grávida 9).

"... Parei de fazer tratamento odontológico na minha primeira gestação há oito anos, pois o dentista falou que não era necessário. Passei a gestação inteira sentindo dor..." (Grávida 1).

"...Coloquei aparelho, mas depois que engravidei não fui mais ao dentista, pra não prejudicar o bebê..."(Grávida 34).

Após os relatos e visões pessoais, foi orientado sobre a realização do pré-natal odontológico e o agendamento da consulta odontológica para avaliação da saúde bucal. 
Não havendo necessidade de tratamento, é aconselhável uma consulta de rotina em cada trimestre da gestação (BRASIL, 2013; 2016b).

Segundo Rocha et al. (2015) a maioria dos tratamentos odontológicos pode ser realizada no período gestacional, incluindo as intervenções de urgência. Em procedimentos envolvendo radiografia, a radiação é mínima e utiliza-se o avental de chumbo que garante a segurança da mãe e do bebê. A anestesia também é segura e evita a dor e o desconforto durante o tratamento odontológico, porém é importante estar avaliando a real necessidade do exame neste período.

\section{Parto Humanizado}

A abordagem do tema parto humanizado é muito esclarecedora para as gestantes. O termo humanizado refere-se a um novo olhar para as mulheres que devem ser respeitadas, informadas de qualquer procedimento a ser realizado, serem incluídas em tomadas de decisões, ter medidas de conforto e alívio da dor, que incluem métodos farmacológicos e não farmacológico, respeitando suas vontades e o seu tempo. Ainda envolve direitos que devem ser conhecidos por todas, como por exemplo, o direito de terem um acompanhante, direito às licenças maternidade e paternidade, bem como ao direito ao aleitamento. Novas técnicas de incentivo ao parto normal têm sido estudadas e aplicadas. Na roda de conversa esclarecemos as diferenças entre o parto natural e a cirurgia cesariana, sobre as vantagens do parto vaginal e os riscos da cesárea (BRASIL, 2017).

Diferentes opiniões foram dadas pelas gestantes em relação ao tipo de parto preferido, indicando ansiedade e medo em relação ao parto natural, principalmente entre as gestantes primigestas e as mães que já passaram por uma cesariana, por sentirem maior segurança neste procedimento. Entre as que passaram pelo parto normal, as opiniões foram bem divergentes, algumas não querendo mais passar por essa experiência e outras com sentimento de segurança, por ter tido um parto tranquilo. Isto indica que as diferenças apresentadas são reflexos do preparo, apoio, e angústias individuais de cada mulher.

Reforçou-se a importância de se realizar o pré-natal adequadamente para garantir parto e nascimento saudável e a disponibilidade da equipe em estar conversando em particular, se necessário. Foram apresentados os sinais de alerta na gravidez como cólica muito forte e frequente, inchaço nos pés, pernas e rosto, sangramento e perda de líquido 
pela vagina, corrimento escuro e redução da movimentação do bebê. Sempre que alguns desses sinais forem observados, orienta-se a procura de atendimento na USF ou outras unidades de pronto atendimento (BRASIL, 2013).

\section{Aleitamento materno e mitos relacionados}

A Política nacional de promoção, proteção e apoio ao aleitamento materno têm como finalidade qualificar o processo de trabalho dos profissionais da saúde, com intuito de reforçar, orientar e incentivar a promoção do aleitamento materno e da alimentação saudável para as crianças menores de dois anos (BRASIL, 2015).

A roda de conversa com o tema amamentação foi iniciada com atividade lúdica de cartas "passa e repassa" em que as gestantes tinham que responder sobre o aleitamento materno e alguns mitos relacionados, de acordo com os próprios conhecimentos. A partir das respostas fornecidas, trabalharam-se conceitos falhos e/ou inadequados, novas informações e incentivo ao aleitamento materno, incluindo as vantagens para a mãe e bebê.

As perguntas avaliaram o conhecimento sobre: colostro, constituição do leite materno, amamentação, uso de chupeta e mamadeira. Durante a discussão do tema foi esclarecido que o leite materno é um alimento completo, exclusivo até os seis meses, que protege contra infecções e evita mortes infantis. $\mathrm{O}$ aleitamento materno possui vantagens para a mãe já que ajuda a voltar ao peso normal, contribui para proteção contra câncer de mama e de ovário e auxilia no vínculo afetivo entre mãe e filho (BRASIL, 2015). Muitas gestantes deixam de amamentar precocemente por não terem informações suficientes, estímulo ou apoio.

O segundo momento foi relacionado a mitos que já ouviram sobre amamentação. $\mathrm{O}$ mito que "a cerveja preta e canjica aumentam a produção de leite"foi o que mais sobressaiu. Consoante o Ministério da Saúde, a ingestão de líquidos z aumentar a produção de leite, porém não são recomendadas bebidas alcoólicas, pois tudo o que a mãe ingere passa para o leite (BRASIL, 2017).

Outro mito prevalente foi "só meu leite não sustenta e o bebê chora de fome". Foi orientado que o leite materno, até os seis meses, é suficiente para saciar a fome e a sede do bebê e outros motivos podem deixá-lo choroso, como a cólica ou por simplesmente por querer estar em contato pele a pele com a mãe (BRASIL, 2017). 
Sobre esse tema percebeu-se o interesse das gestantes sobre o assunto, onde teve mais participação, além de troca compartilhada das suas experiências.

\section{Primeiros cuidados com o recém-nascido}

$\mathrm{Na}$ abordagem dos primeiros cuidados com o recém-nascido, foi explanado a preciosidade da realização de cada exame, alguns realizados ainda na maternidade,obrigatórios e gratuitos, que são oferecidos pelo Sistema Único de Saúde (SUS): o teste do pezinho, o teste da orelhinha e o teste do olhinho (BRASIL, 2012).

Houve demonstração prática da técnica correta de higienização na troca da fralda, banho, bem como a desinfecção do coto umbilical com álcool $70 \%$ para uma boa cicatrização. Cuidados com a pele frágil do bebê também foi abordado, assim como minimizar as cólicas presentes nos três primeiros meses de vida, comuns devido ao sistema digestivo que não está completamente formado. Percebeu-se que as gestantes demonstraram interesse pelo tema pela verbalização do conhecimento prévio, no que diz respeito aos principais cuidados de higiene com o recém-nascido, partindo de uma cultura comunitária e de orientações passadas por seus familiares.

\section{Manobra de desobstrução de vias aéreas (Técnica de Heimlich)}

O engasgo em bebês representa um importante acidente doméstico, em crianças menores de um ano de idade e, que pode levar à morte por obstrução das vias aéreas. Por esse motivo, escolheu-se explicar que a obstrução pode ser parcial ou total, como identificá-las e ensinar a Manobra de Heimlich. Quando a obstrução é parcial, o bebê apresenta respiração dificultada e ruidosa, tosse silenciosa, cianose, incapacidade para falar ou respirar. Na obstrução total, ocorre asfixia, inconsciência até o mesmo o óbito (BRASIL. Ministério da Saúde. Secretaria da Atenção a Saúde..., 2016). Em ambos os casos, a ação rápida pode salvar a vida.

Entre as principais causas de obstrução das vias aéreas está a aspiração de leite regurgitado, consequência de uma amamentação rápida, aspiração de objetos como balas, moedas e outros (BRASIL. Ministério da Saúde. Secretaria da Atenção a Saúde..., 2016). Desta forma foram citadas medidas preventivas como amamentar em local tranquilo e manter o bebê mais ereto possível, para que o leite possa adentrar melhor ao sistema digestivo; prestar atenção nos acessórios das roupas e kits de berço e utilizar brinquedos 
adequados à faixa etária da criança. Ainda, ter sempre acessível o número telefônico dos serviços de urgência e emergência, tanto dos bombeiros (193) como do Serviço de Atendimento Móvel de Urgência (SAMU) que é o 192 (BRASIL. Ministério da Saúde. Secretaria da Atenção a Saúde..., 2016).

Posteriormente procedeu-se uma demonstração da técnica de desobstrução das vias aéreas de recém-nascido utilizando boneca. Em seguida, realizou-se a dinâmica com as gestantes ensinando-as, passo a passo, a realizar a manobra de Heimlich. O treinamento se deu de forma individual, tendo uma atenção especial a cada participante.

É preconizado duas atividades educativas grupais pelo protocolo da Linha Guia Mãe Paranaense, independente do risco gestacional presente (PARANÁ, 2018). No evento relatado, se a gestante iniciou o pré-natal ainda no primeiro trimestre, o número de participações foi de quatro a cinco encontros, em média, estando bem acima do recomendado.

\section{CONCLUSÃO}

A realização deste projeto proporcionou à acadêmica oportunidade de vivência profissional, responsabilizando-a na elaboração e coordenação de atividades grupais, estabelecendo maior compreensão neste período único da vida da mulher.

Os momentos vividos estabeleceram conhecimento, compreensão, identificação da realidade deste processo, mediante a relação coletiva através do diálogo, refletindo as potencialidades e limitações referentes à saúde gestacional, reafirmando que ações de promoção à saúde devem ser participativas e transformadoras, trazendo possibilidades de intervenções no melhoramento futuro.

Observou-se que o projeto de intervenção com o grupo de gestantes da zona rural proporcionou resultados expressivos, servindo assim como complemento ao acompanhamento pré-natal, estabelecendo uma melhor qualidade na assistência, esclarecimentos de dúvidas, compartilhamento de experiências, maior integração das gestantes com a equipe de saúde pelo acolhimento humanizado, proporcionando mais segurança e afetividade. 
Embora em meio às adversidades encontradas na zona rural ao acesso a USF, como distância, meio de transporte, mudanças climáticas já relatadas em outros estudos, o grupo de intervenção conseguiu conscientizar sobre a relação entre acompanhamento pré-natal e saúde materno-infantil. Isto pode ser evidenciado, pois mesmo com as dificuldades, não deixaram de comparecer às consultas e dos encontros de educação em saúde, havendo um feedback positivo entre as gestantes e a comunidade.

Este acompanhamento permitiu detectar a falta de se trabalhar outros assuntos como planejamento familiar, atividade sexual durante a gestação, orientações específicas para gestantes da zona rural que muitas vezes trabalham em lavouras, hortas, cuidados com animais, entre outros. Ainda, desenvolver ações junto à comunidade escolar, principalmente adolescentes, que envolva temas DST, métodos contraceptivos e relacionamento afetivo responsável.

Diante da constatação que o pré-natal odontológico era deficiente, viu-se a necessidade de formar novas parcerias com projetos da UEPG, na área de odontologia, que atuassem na região de Itaiacoca. Foi implantado o evento "Linha de Cuidado à gestantes da comunidade rural de Itaiacoca", acrescentando às atividades a avaliação da saúde bucal e atendimento clínico. Neste momento inicial, infelizmente só contemplamos as gestantes da USF do CRUTAC, onde atuam os projetos de extensão "Atuação dos pósgraduando de Odontologia (Lato senso, Stricto senso e Residências) no Programa Centro

Rural de Treinamento e Ação Comunitária - CRUTAC" e "Ação Integrada na Comunidade Pacientes Adultos e Idosos".

\section{AGRADECIMENTOS E APOIO}

Os autores são gratos a Pró-Reitoria de Extensão e Assuntos Culturais da UEPG/Fundação Araucária (Programa de Inclusão Social em Atividades de Extensão Universitária) e às gestantes de Itaiacoca que possibilitaram a realização deste trabalho.

\section{REFERÊNCIAS}

BARBOSA, E. M. et al. Perfil sociodemográfico e obstétrico de parturientes de um 
hospital público. Revista da Rede de Enfermagem do Nordeste - Rev Rene, Ceará, v.18, n.2, p.227-233, 2017.

BORGES, V. P. Educação e promoção da saúde no pré-natal. 2015. Trabalho de conclusão de curso (Graduação) - Escola de Enfermagem, Universidade Federal do Rio Grande do Sul, Rio Grande do Sul, 2015. Disponível em: https://lume.ufrgs.br/bitstream/handle/10183/135527/000987931.pdf?sequence=1\&is Allowed=y. Acesso em: 16 out. 2018.

BRASIL. Lei no 7.498, de 25 de junho de 1986. Dispõe sobre a regulamentação do exercício da enfermagem e dá outras providências. Diário Oficial da União, Brasília, DF., 26 jun. 1986. Seção 1, p. 10.

BRASIL. Ministério da Saúde. Banco de leite: Mitos e verdades. Governo Federal, Brasília: Ministério da Saúde; 2017. Disponível em: http://portalms.saude.gov.br/artigos/724-acoes-e-programas/banco-deleitehumano/41044-mitos-e-verdades. Acesso em: 24 maio 2019.

BRASIL. Ministério da Saúde. Biblioteca Virtual em saúde. Importância do PréNatal. Brasília: Ministério da Saúde, jan. 2016a. Disponível em: http://bvsms.saude.gov.br/dicas-em-saude/2198-importancia-do-pre-natal. Acesso em: 12 out. 2018.

BRASIL. Ministério da Saúde. Caderneta da Gestante. 3. ed. Brasília-DF., 2016b. Disponível em: http://portalsaude.saude.gov.br/images/pdf/2016/marco/01/Caderneta GestInternet.pdf. Acesso em: 16 out. 2018.

BRASIL. Ministério da Saúde. Protocolos da Atenção Básica: saúde das mulheres. Brasília: Ministério da Saúde, 2016c. 230p. Disponível em: http://bvsms.saude.gov.br/bvs/publicacoes/protocolos_atencao_basica_saude_mulheres. pdf. Acesso em: 23 maio 2019.

BRASIL. Ministério da Saúde. Diretrizes nacionais de assistência ao parto normal: versão resumida [recurso eletrônico]. Brasília: Ministério da Saúde, 2017. 51 p. Disponível em: http://bvsms.saude.gov.br/bvs/publicacoes/diretrizes_nacionais_assistencia_parto_norm al.pdf. Acesso em: 21 maio 2019.

BRASIL. Ministério da Saúde. Secretaria de Atenção à Saúde. Departamento de 
Atenção Básica. Atenção ao pré-natal de baixo risco [recurso eletrônico] . 1. ed. rev. Brasília: Editora do Ministério da Saúde, 2013. 318 p.: il. - Cadernos de Atenção Básica, $\mathrm{n}^{\circ} \quad 32$. $\quad$ Disponível em: http://189.28.128.100/dab/docs/portaldab/publicacoes/caderno_32.pdf. Acesso em: 28 maio 2019.

BRASIL. Ministério da Saúde. Secretaria de Atenção à Saúde. Departamento de Ações Programáticas Estratégicas. Atenção à saúde do recém-nascido: guia para os profissionais de saúde. 2. ed. - Brasília : Ministério da Saúde, 2012. 4 v. Disponível em: http://bvsms.saude.gov.br/bvs/publicacoes/atencao_saude_recem_nascido_profissionais _ v1.pdf. Acesso em: 01 jun. 2019.

BRASIL. Ministério da Saúde. Secretaria de Atenção à Saúde. Departamento de Atenção Básica. Saúde da criança: aleitamento materno e alimentação complementar. 2. ed. - Brasília: Ministério da Saúde, 2015. 184 p. : il. - (Cadernos de Atenção Básica; n. 23). Disponível em: http://bvsms.saude.gov.br/bvs/publicacoes/saude_crianca_aleitamento_materno_cab23. pdf. Acesso em: 27 maio 2019.

BRASIL. Ministério da Saúde. Secretaria da Atenção a Saúde. Protocolos de Intervenção para o SAMU 192 - Serviço de Atendimento Móvel de Urgência. Brasília: Ministério da Saúde, 2016. Disponível em: http://bvsms.saude.gov.br/bvs/publicacoes/protocolo_suporte_basico_vida.pdf. Acesso em: 02 jun. 2019.

CAIRES, E. S.; SANTOS JUNIOR, P. J. dos. Territorialização em saúde: uma reflexão acerca de sua importância na atenção primária. Territorialization in health: a reflection on their importance in primary attention, Revista Eletrônica Acervo Saúde REAS, Campinas -São Paulo, v.9, n.1, p.1174-1177, abr. 2017. Disponível em: https://www.acervosaude.com.br/doc/REAS2.pdf. Acesso em: 14 mar. 2019.

CAMILLO, B. S. et al. Ações de educação em saúde na atenção primária a gestantes e puérperas. Revisão integrativa; Revista de Enfermagem UPFE, Recife, v.10, supl. 6, p.4894-901, dez. 2016. Disponível em: https://periodicos.ufpe.br/revistas/ revistaenfermagem/article/download/11270/12905. Acesso em: 17 out. 2018.

CARRACA, L. R. G.; OLIVEIRA. J. P. Atuação do Enfermeiro na Educação em 
Saúde Durante o Pré-Natal: uma Revisão Bibliográfica. Revista Fafibe On-line, Bebedouro-SP, Ano VI, n. 6, p.96-109, nov. 2013. Disponível em: http://www.unifafibe.com.br/revistasonline/arquivos/revistafafibeonline/sumario/28/111 22013185545.pdf. Acesso em: 12 out. 2018.

CUNHA, A. J. L. A. da; LEITE, A. J. M.; ALMEIDA, I. S. de. Atuação do pediatra nos primeiros mil dias da criança: a busca pela nutrição e desenvolvimento saudáveis. Jornal de Pediatria (Rio J.), Porto Alegre ,v. 91, n. 6, supl. 1, p. S44-S51, jun. 2015. DOI: 10.1016/j.jped.2015.07.002. Disponível em: http://www.scielo.br/pdf/jped/v91n6s1/0021-7557-jped-91-06-s1-0s44.pdf. Acesso em: 05 jun. 2019.

JUSTUS, L. G. et al. A territorialização na Atenção Básica: um relato de experiência na formação médica. Interface comunicação saúde educação, Botucatu, São Paulo, v.1 , suplemento 1, p.1345-54, 2017. DOI: 10.1590/1807-57622016.0512. Disponível em: http://www.scielo.br/pdf/icse/v21s1/1807-5762-icse-21-s1-1345.pdf. Acesso em: 01 jun. 2019.

LEITE, M. G. et al. Sentimentos advindos da maternidade: revelações de um grupo de gestantes. Psicologia em Estudo, Maringá, v. 19, n. 1, p. 115-124, jan/mar. 2014. DOI: $\quad 10.1590 / 1413-7372217650011 . \quad$ Disponível em: http://www.scielo.br/pdf/pe/v19n1/12.pdf. Acesso em: 24 abr. 2019.

MELO. R. H. V. et al. Roda de Conversa: uma Articulação Solidária entre Ensino, Serviço e Comunidade. Revista Brasileira de Educação Médica, v.40, n.2, p. 301 - 309, 2016. Disponível em: http://www.scielo.br/pdf/rbem/v40n2/1981-5271-rbem-40-20301.pdf. Acesso em: 10 jun. 2019.

PARANÁ. Secretaria de Saúde do Estado do Paraná. Linha Guia Mãe Paranaense. $7.2018 . \quad$ Ed. Disponível em: http://www.saude.pr.gov.br/arquivos/File/LinhaGuiaMae Paranaense_2018.pdf. Acesso em: 19 abr. 2019.

PAULA, M. C. Dificuldade na adesão ao pré-natal na zona rural de Perdizes/MG: Uma proposta de intervenção. 2013. 28f. Trabalho de conclusão de curso Monografia (Especialização em Atenção Básica em Saúde da Família). Universidade Federal do Triângulo Mineiro. Uberaba, 2015. Disponível em 
https://www.nescon.medicina.ufmg.br/biblioteca/registro/Dificuldades_na_adesao_ao_p re_natal_na_zona_rural_de_Perdizes_MG_uma_proposta_de_intervencao/461.

Acesso em: 10 nov. 2018.

PRIMEIROS 1000 dias. 2016. Disponível em: http://primeiros1000dias.com.br/acausa/o-que-e/. Acesso em: 02 jun. 2019.

QUEROZ, A. A. de. Conhecendo as alterações da gestante para um melhor cuidar no pré-natal. 2012. 33f. Trabalho de conclusão de curso, Monografia (Especialização em Atenção Básica em Saúde da Família). Universidade Federal de Minas Gerais. Faculdade de Medicina. Núcleo de Educação em Saúde Coletiva. Brumadinho, 2012. Disponível em: https://www.nescon.medicina.ufmg.br/biblioteca/imagem /3819.pdf. Acesso em: 12 out. 2018.

RESES, M. L. N. Universalidade do acesso e integridade na atenção à saúde bucal. 2017. 152 f. Tese (Doutorado) - Curso de Saúde Coletiva, Universidade Estadual de Santa Catarina, Florianópolis, 2017. Disponível em: https://repositorio.ufsc.br/handle/123456789/189121. Acesso em: 03 jun. 2019.

ROCHA, J. S. R. et al. Cartilha de Gestante: cuidado com a saúde bucal. Ponta Grossa: Universidade Estadual de Ponta Grossa - Programa de Pós-Graduação em Odontologia, 2015.

Disponível em: http://www.saude.pr.gov.br/arquivos/File/CartilhadaGestante.pdf. Acesso em: 04 abr. 2016.

SCHAFRANSKI, Antonio Carlos. Iniciativas metodológicas para a melhoria de aproveitamento do estágio supervisionado em análises clínicas no programa CRUTAC - PG. Imprensa Universitária: Ponta Grossa, 1982. 60p.

ROCHA, I. M. S. da; BARBOSA, V. S. S. de; LIMA, A. L. S. Fatores que influenciam a não adesão ao programa de pré-natal. Revista Científica de Enfermagem, São Paulo, v. 7, n.21, p.21-29, 2017.

TEIXEIRA; D. et al. Alimentação e nutrição na gravidez. Programa Nacional para Promoção da Alimentação Saudável, Lisboa, Portugal, 2015. 28p. Disponível em: https://www.alimentacaosaudavel.dgs.pt/activeapp/wpcontent/files_mf/1444899925Ali mentacaoenutricaonagravidez.pdf. Acesso em: 19 maio 2019. 
DOI: http://dx.doi.org/10.5380/ef.v0i20

Recebido em: 24 de outubro de 2020.

Aceito em: 12 de janeiro de 2021. 